\title{
STATUS OF PRODUCTION, DISTRIBUTION AND DETERMINANTS OF BIOMASS BRIQUETTE ACCEPTABILITY IN KAMPALA CITY, UGANDA
}

\author{
P. Mugabi ${ }^{1, \diamond}$ D.B. Kisakye ${ }^{1}$
}

\begin{abstract}
Biomass briquettes have been identified as a plausible and close alternative to commonly used energy fuels such as charcoal and firewood whose prices are escalating due to the dwindling natural resource base. However, briquettes do not seem to be as popular as would be expected. This study assessed the production, distribution and acceptability of the briquettes in Kampala district. A total of 60 respondents, 50 of whom were briquette users and 10 briquette producers were sampled from five divisions of Kampala district to evaluate consumer acceptability, preference for briquette type and shape. Households and institutions were identified to be the major consumers of briquettes while community-based organizations were the major distributors of briquettes. The Chi square test of independence showed significant association between briquette acceptability and briquette attributes of substitutability and low cost $(p<0,05)$. The Kruskal Wallis test showed that low income class people preferred non-carbonized briquettes. Gender, marital status and income level also cause variation in preference for spherical, stick and honey comb briquettes $(\mathrm{p}<0,05)$. The major challenges faced by briquette users in Kampala were; production of a lot of ash, frequent crushing and limited access of briquettes. The producers of briquettes were mainly challenged by regular machine breakdown, raw material scarcity and poor carbonizing units. It was concluded that briquettes have market and are generally accepted in Kampala. However, user preferences need to be taken into account by briquette produces, suitable cook stoves should be availed to users and there is need for standards to ensure quality of briquettes.
\end{abstract}

Keywords: Biomass, biomass residues, briquettes distribution, briquette producers, consumer acceptability, marketability.

\section{INTRODUCTION}

The majority of the populations in developing countries completely thrive on traditional fuels such as wood fuel, using inefficient conversion technologies to meet their energy demands. Over $90 \%$ of the Ugandan population rely on biomass fuel for cooking and heating (Bagabo et al. 2014). This is because there is inadequate supply of reliable and affordable clean energy. Over reliance on wood fuel coupled with the increasing population in developing countries, have put forests under immense pressure moreover at the time when the world is concerned about the changing climate and the need to conserve these resources. Bagabo et al. (2014) observed that with the population increasing at a rate of 3,6\% per annum, the increasing demand for charcoal and fuel wood that is fueling large scale charcoal production will increasingly become a major cause of deforestation and climate related disasters. This consequently indicates an imminent crisis period in the charcoal production zones by 2019 as projected by Namaalwa et al. (2009). This has created a need to find alternative, affordable energy sources to relieve pressure on the dwindling forest resources. Substantial quantities of biomass residues generated as waste from commercial forestry, agricultural and industrial sectors (Njenga et al. 2009) have been considered as potential alternative sources of energy. These residues are currently either

\footnotetext{
${ }^{1}$ Makerere University, Department of Forestry Biodiversity and Tourism. Kampala. Uganda

•Corresponding author: pkmugabi@gmail.com

Received: 09.03.2018 Accepted: 28.10.2020
} 
burned without heat recovery or left to rot, subsequently emitting Green House Gases (GHGs). Estimates from Sub-Saharan Africa (SSA) indicate that as much as 1000 million metric tonnes (mt) and $140 \mathrm{mt}$ are generated annually from the forestry and agricultural sectors, respectively (Dasappa 2011).

In Uganda, biomass residues are one of the sources of energy with great growth potential in the coming years because $1,2 \mathrm{mt}$ and $1500 \mathrm{mt}$ are generated daily from agricultural residues and municipal solid waste respectively (MEMD 2016, Fund 2003). The, use of biomass raw materials as well as waste has been embraced through briquetting to reduce pressure on natural forest biomass. Briquettes are an alternative fuel source currently gaining attention in Uganda. Briquettes are composed of low bulk density, high moisture content and irregularly shaped and sized organic household waste, such as peanut shells, banana peels, corn husks, sawdust, charcoal fines. Briquetting involves compaction of residues into a product of higher density than the original raw materials (Oladeji 2015). Carbonized or non-carbonized residues are compressed by hand or briquette machine into solid masses of uniform shape and size referred to as carbonized or non-carbonized briquettes (Karunanithy et al. 2012). Opportunities for briquette in Uganda are; the increasing demand and cost of charcoal and firewood, presence of unused domestic, municipal and agricultural waste, lower cost relative to charcoal and firewood and the quest for eco-friendly fuels. The market for briquettes in Uganda is segmented depending on user preferences and characteristics. Carbonized briquettes act as a replacement for charcoal for domestic and institutional cooking and heating where they are preferred by market segments like households, poultry breeders, restaurants, schools and hospitals for their smoke lessness and more consistent heat output. However, the size and shape for each segment may differ. Non carbonized briquettes are an alternative to firewood and raw biomass fuel. These are more appropriate for industrial processes, institutions where emissions can be controlled and rural households because they have a higher energy per unit weight than firewood and raw biomass (Spirchez et al. 2018). Briquetting technology has been in Uganda for more than a decade but briquettes are still not popular to date despite the availability of biomass raw material and waste, not to mention the ever-soaring charcoal prices. The objectives of this study were: (1) to identify the producers and/or dealers and consumers along the briquette value chain; (2) to evaluate consumer preference for briquettes based on type and shape; (3) to assess the socio-economic factors and briquette attributes that influence briquette acceptability: and (4) to assess the challenges faced in production and use of biomass briquettes.

\section{MATERIALS AND METHODS}

\section{Study area}

The study was conducted in Kampala district. The district doubles as the capital city and major commercial hub of the country. Administratively, Kampala district is divided into 5 divisions and has a population density of 8646,9 people per $\mathrm{km}^{2}(\mathrm{UBOS} 2014)$. It is located $32^{\circ} \mathrm{E}$ and $15^{\prime \prime} \mathrm{E}$ of the Greenwich, $0^{\circ}$ and $19 \mathrm{~N}$ of the equator and is bordered by Wakiso and Mukono Districts to the North East and South-West respectively. The district was chosen as a study area because it is here that people use the highest quantity of charcoal and it is most expensive in Kampala as well (MEMD 2016). The district was also considered because it had a high and diverse population of small scale briquette producers and consumers than any other part of Uganda. Five divisions; Rubaga, Kawempe, Kampala Central, Makindye and Nakawa were surveyed.

\section{Sampling and data collection}

Multistage sampling method was used to choose 50 briquette users and 10 producers from the five divisions of Kampala. At the first stage, two of the parishes in each division were purposively selected. The parishes were selected using two criteria: (1) Being residential and (2) having substantially large populations of the urban poor. The selected parishes were Kyambogo and Kyanja in Nakawa division, Ndeeba and Kawaala parishes in Rubaga division, Katwe and Kisugu for Makindye division, Mpererwe and Kawempe parishes in Kawempe division; and Kamwookya and Old Kampala in Kampala Central. At the second stage, in each parish five briquette users and one producer were selected. First, snow ball sampling was used to identify briquette users in each of the selected parish since they were very few and hard to find. The producers on the other hand were randomly selected with the aid of the Global Village for Energy Partnerships (GVEP) lists.

A survey was then conducted using two semi structured questionnaires, one for briquette users and the other for producers. The user's questionnaire was used to establish socio economic factors and briquette attributes affecting acceptability, preferences for briquette shape, type and other attributes and challenges faced by users while using briquettes (Figure 1). The producer questionnaire was used to collect data on briquette 
preference, marketability and challenges faced in briquette production. Key informant interviews were also administered to persons and institutions deemed to have distinguished knowledge on briquettes.

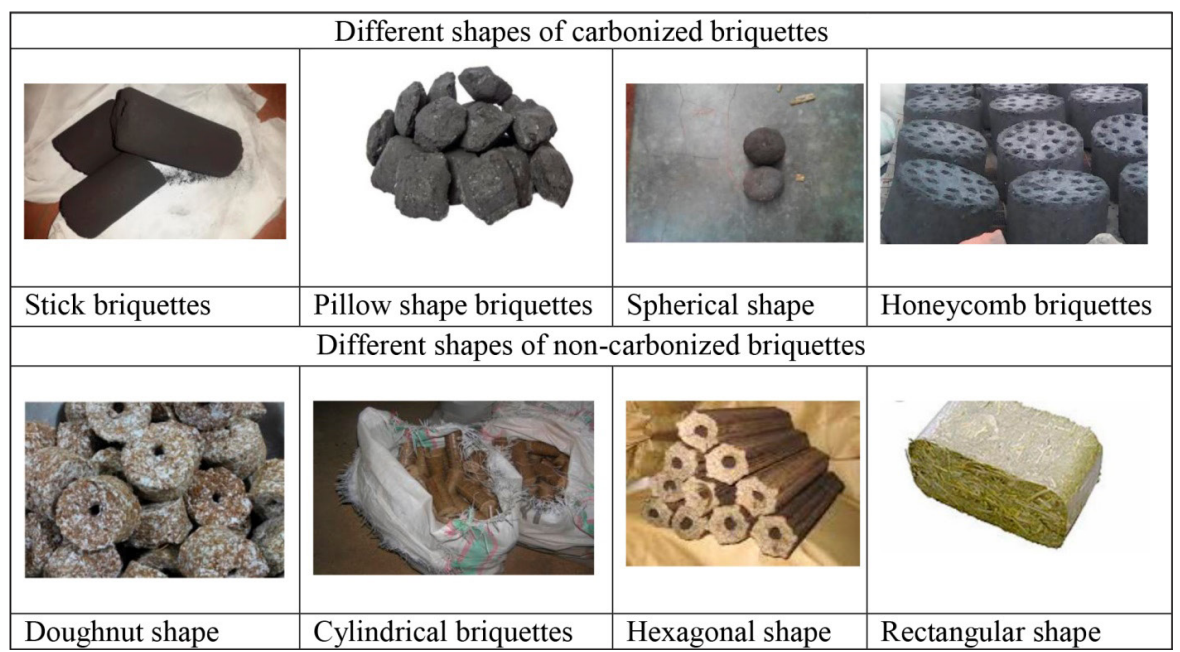

Figure 1: Briquette types and shapes.

\section{Data analysis}

Univariate analysis was carried out to obtain patterns of distribution and dispersion of responses on respondent demographics, major distributors and consumers of briquettes, and challenges faced by briquette users and producers. Since data were not normally distributed, nonparametric tests were used. The Kruskal-Wallis test was used to analyze differences in preference for briquette type and shape based on the different demographic variables that included; gender, age, marital status, education level and monthly income. The Chi square test of independence was also used to show association of briquette attributes, and socio-economic factors with briquette acceptability.

\section{RESULTS AND DISCUSSION}

\section{Stakeholders in the briquette value chain}

Most of the producers (70\%) were relatively new in the business having spent less than 5 years in briquette production. Sixty percent of the respondents produced more than one tonne of briquettes monthly. Majority $(60 \%)$ of the respondents produced briquettes on a daily basis and only $10 \%$ of the respondents produced briquettes on a monthly basis. This implies that briquetting is a relatively new technology in Kampala and the potential producers have low technological capacity because they use; drums for carbonization, manual extruders for briquetting and the sun for drying briquettes. The average production rate also indicates that briquettes have ready market but the supply is still limited.

Majority (32\%) of the briquette consumers were households followed by poultry breeders (24\%) while the rest where institutions such as schools, hotels and restaurants. It seems the quality of briquettes currently on market does not meet the energy needs of most commercial users, yet to sustain this industry commercial users usually play a pivotal role. The main distributors of briquettes were Community Based Organizations (CBOs) $(36 \%)$, fuel vendors $(27 \%)$ and supermarkets $(23 \%)$. CBOs emerged the main distributors because they often undertake this as a corporate social responsibility to protect the environment by availing alternative energy sources. The CBOs mainly target households, another reason perhaps as to why households were the leading user of briquettes. In order to increase briquettes on the market perhaps conventional wood fuel distributors need to be encouraged to stock briquettes to common markets where consumers can easily access them. 


\section{Briquette acceptability}

\section{Briquette characteristics and acceptability}

All respondents had knowledge about carbonized briquettes and an excellent preference for them (Figure 2 ). Conversely, majority of the respondents $(72 \%)$ had no idea about non carbonized briquettes and had limited preference for them (Table 1). According to (Mahoro et al. 2017, Ferguson 2012), the knowledge and excellent preference for the carbonized type is due to the fact that carbonized briquettes produce no soot, are easily accessible and are compatible with most of the commonly used charcoal stoves in Kampala. The low preference for non-carbonized briquettes could probably be attributed to the lack of stoves that are directly compatible with these briquettes and the production of soot during combustion. Perhaps if briquette production was complimented with production of appropriate designs of stoves suitable for either type of briquettes, briquette marketability and acceptability could have been better.

For briquette shapes, spherical briquettes were mostly known and preferred (64\%) by the respondents followed by stick briquettes $(60 \%)$ and doughnut shape briquettes (Figure 3 ). The spherical briquettes were most preferred by most respondents due to their ease of manufacture and access. This was in particular the case for low income groups that constituted the largest percentage of this study. Stick briquettes have an aperture that allows air flow and consistent heat output which justifies their preference after the spherical shaped. This concurs with Spirchez et al. (2018) who suggests that a hollow core makes a major contribution to the combustion process, as fire may enter through the hollow core. Consequently, the combustion flame covers a larger area of the briquette, thus increasing the burn temperature and the energy release speed. Stick briquettes are also uniform in size and can easily be broken into the desired smaller sizes by users depending on stove size. Stick briquettes were followed by doughnut shaped, honey comb and pillow shaped briquettes respectively in levels of preference. This order of preference probably stems from the fact that doughnut shaped briquettes are cumbersome to make domestically, honey comb briquettes require directly compatible stoves while pillow shaped briquettes are rare on the market.

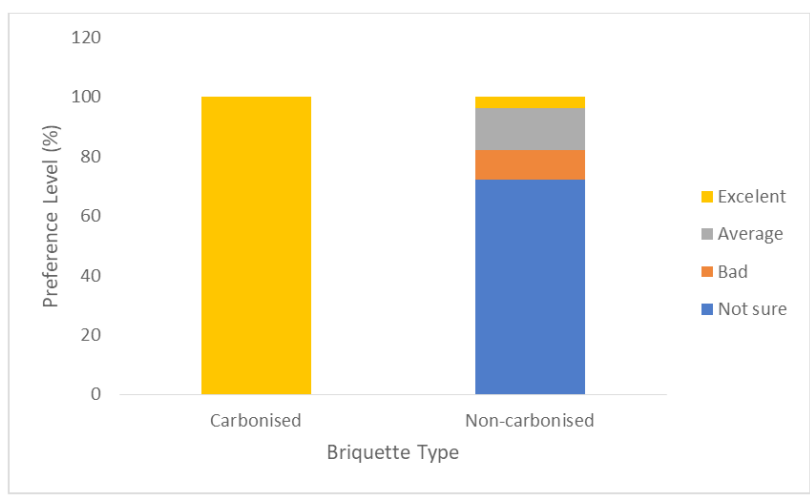

Figure 2: Preference for briquette type.

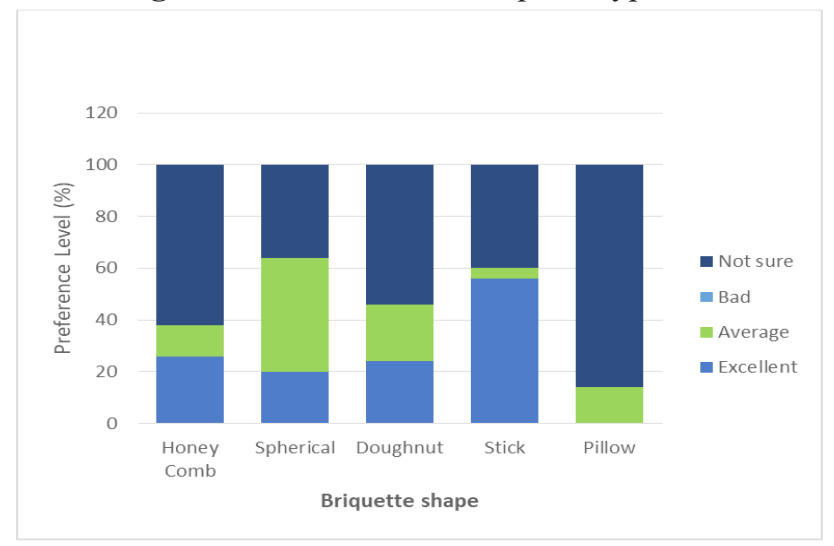

Figure 3: Preference for briquette shape. 
Majority of the respondents $(60 \%)$ were satisfied and willing to continue using briquettes while the rest $(40 \%)$ were not satisfied and not willing to continue using briquettes. The willingness to continue using briquettes may be attributed to the increased policy demands in the country that are discouraging the use of unsustainable fuels like charcoal while promoting use of alternative fuels such as briquettes that reduce on deforestation. The underlying reasons for unwillingness to continue using briquettes may probably be poor quality of the briquettes which results from weak or absence of technological capacity to properly densify the briquettes (Mwampamba et al. 2013) and the need for a few lumps of charcoal to light briquettes.

\section{Socio economic factors and briquette acceptability}

There was significant $(\mathrm{P}<0,05)$ variation in preference for non-carbonized briquettes with monthly income. This was probably because low income households could not afford carbonized briquettes. Since the non-carbonized briquettes were cheaper than carbonized briquettes, it was the affordable choice for the poorer households. These findings disagree with Mutea (2015) assertion that adoption of improved biomass technologies is not necessarily dependent on household income since people being rational have their own priority of problems. There was significant $(\mathrm{P}<0,05)$ variation in choice of spherical briquettes with gender and income level, choice of stick briquettes with marital status and level of income and choice of honey comb briquettes with income level (Table 1). Women preferred spherical briquettes perhaps because it is easy to make at home and could serve both as a household business and as a supplement to household energy needs. Women also tend to have more time at home compared to men and can be in directly in-charge of such a business. Under marital status, the single individuals preferred stick briquettes probably because these briquettes ignite fast and can cook faster the simple, small quantity meals this category of people normally prepare (Mahoro et al. 2017). Stick briquettes were also preferred by higher income respondents because of their ease of use. The honeycomb and spherical briquettes were mostly preferred by low income respondents probably due to low cost and ease of domestic manufacture respectively.

Table 1: Kruskal Wallis test results for variation of briquette shape preference with gender, age, marital status, education level and income with briquettes shapes.

\begin{tabular}{|c|c|c|c|c|}
\hline Socio-Demographic variables & Briquette shape & $\mathrm{X}^{2}$ & d.f & P-Value \\
\hline \multirow[t]{5}{*}{ Gender } & Honey Comb & 0,184 & l & 0,668 \\
\hline & Spherical & 4,110 & 1 & $0,043^{*}$ \\
\hline & Doughnut & 0,073 & 1 & 0,786 \\
\hline & Stick & 0,004 & 1 & 0,950 \\
\hline & Pillow Shape & 0,001 & 1 & 0,981 \\
\hline \multirow[t]{5}{*}{ Age } & Honey Comb & 4,038 & 3 & 0,082 \\
\hline & Spherical & 5,053 & 3 & 0,102 \\
\hline & Doughnut & 3,012 & 3 & 0,332 \\
\hline & Stick & 5,709 & 3 & 0,226 \\
\hline & Pillow Shape & 3,475 & 3 & 0,416 \\
\hline \multirow[t]{5}{*}{ Marital Status } & Honey Comb & 2,658 & 2 & 0,074 \\
\hline & Spherical & 1.403 & 2 & 0,235 \\
\hline & Doughnut & 4,481 & 2 & 0,106 \\
\hline & Stick & 10,431 & 2 & $0,016^{*}$ \\
\hline & Pillow Shape & 0,098 & 2 & 0,933 \\
\hline \multirow[t]{5}{*}{ Education Level } & Honey Comb & 6,637 & 4 & 0,156 \\
\hline & Spherical & 4,937 & 4 & 0,294 \\
\hline & Doughnut & 2,148 & 4 & 0,709 \\
\hline & Stick & 3,990 & 4 & 0,407 \\
\hline & Pillow Shape & 2,404 & 4 & 0,662 \\
\hline \multirow[t]{5}{*}{ Income Level } & Honey Comb & 6,678 & 3 & $0,005^{*}$ \\
\hline & Spherical & 4,732 & 3 & $0,021^{*}$ \\
\hline & Doughnut & 11,213 & 3 & 0,196 \\
\hline & Stick & 7,860 & 3 & $0,049^{*}$ \\
\hline & Pillow Shape & 2,429 & 3 & 0,204 \\
\hline
\end{tabular}

*Significant variation. 


\section{Briquette attributes and acceptability}

All respondents $(100 \%)$ acknowledged that briquettes are a good energy source and were able to substitute conventional fuels $(78 \%)$ while $54 \%$ indicated that briquettes were easy to produce therefore not labour intensive. Eighty eight percent of the respondents considered briquettes to be a cheaper fuel compared to other conventional fuels (Figure 4).

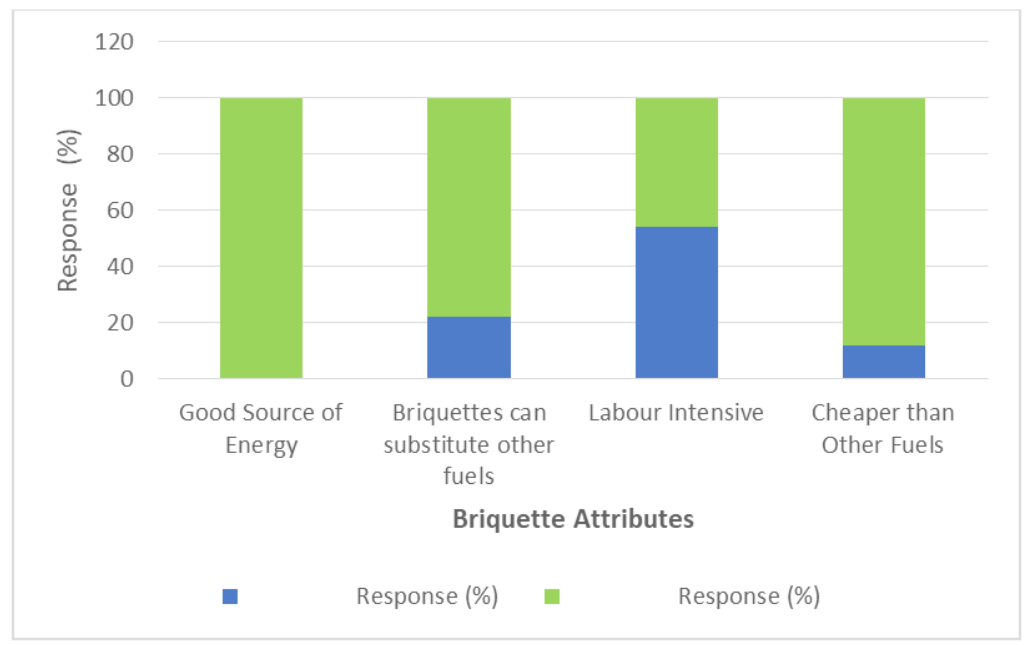

Figure 4: Consumer perception on briquette attributes.

The chi-Square test showed a significant $(\mathrm{p}<0,05)$ relationship between price of briquettes and acceptability as well as ability of briquettes to substitute other fuels and acceptability $(\mathrm{p}<0,05)$ as summarized in Table 2 . The association between briquettes attributes of price and substitutability with briquette acceptability may be attributed to the escalating prices of the commonly used wood fuels. As such, consumers are prompted to look out for cheaper alternatives. This is in tandem with (Akowuah et al. 2012).

Table 2: Chi-Square analysis on effect of briquette attributes on consumer acceptability.

\begin{tabular}{|c|c|c|c|}
\hline Briquette Attributes & $\mathrm{X}^{2}$ & D.F & P-Value \\
\hline Briquettes can substitute other fuels & 15,8 & 1 & $0,000^{*}$ \\
\hline Labour intensive & 0,32 & 1 & 0,582 \\
\hline Cheaper than Other Fuels & 28,88 & 1 & $0,000^{*}$ \\
\hline
\end{tabular}

*Significant association.

\section{Challenges faced in briquette production and use challenges faced by producer of briquettes}

Majority $(80 \%)$ of the producers indicated that most consumers have a negative attitude towards briquettes which affected the marketability of briquettes. This is possibly attributed to difference in social cultural norms of consumers. According to Mwampamba et al. (2013), the key element in fighting the negative barriers of social norms is understanding the local consumer culture and social acceptance of innovation particularly the challenge of introducing new products to the market. Raw material scarcity was another challenge identified by the respondents $(70 \%)$. Other challenges which were identified by the producers were: high marketing costs, shortage of skilled labor and lack of room for expansion. Raw material paucity reduces production capacity and economic returns. This could be attributed to the multiple uses of the raw materials for other purposes and their seasonal nature. In addition, majority of the raw materials are located in rural areas while most of producers are located in peri-urban settlements. This makes it costly to transport the material which hence affects 
the production process.

\section{Challenges to consumers}

Majority $(55,8 \%)$ of the consumers considered briquettes to produce a lot of ash with an ash content of approximately $20-30 \%$ (Sseruwagi and Bukenya 2016) as compared to lump charcoal which varies between $1-5 \%$ basing on species for common charcoal species such as Alibizia zygia, Acacia siberiana and Acacia seyal. This is attributed to lack of clear standards for briquettes and presence of different briquetting recipes even within the same operation which jeopardizes the quality of briquettes. Other challenges reported related to the quality and access to briquettes i.e. briquettes crushing easily $(37,2 \%)$ and not readily available in the different markets as compared to other conventional fuels like charcoal and firewood. Another major challenge identified was limited knowledge and information on how to use the briquettes which has resulted to poor practices such as using water to put out fire after cooking.

\section{CONCLUSIONS}

The main stakeholders in briquette consumption and distribution were households and Community based organizations respectively.

Socio economic factors i.e. income level, marital status and gender influenced consumer acceptability of non-carbonized briquettes, stick, spherical and honey comb briquettes.

Briquette attributes i.e. substitutability and lower price were the most valued by the users and consequently the ones that influenced their (users') acceptability the most.

Majority of the people preferred carbonized briquettes to non-carbonized briquettes and regarding shape, they mostly preferred stick and spherical briquettes.

\section{RECOMMENDATIONS}

Briquette producers consider user preferences and other market demands such as price in order to satisfy their customers.

Avail consumers with energy efficient cook stoves that are directly compatible with the types and shapes of briquettes they use.

National standards on briquette characteristics are established and adopted so as to curtail producers that disseminate low quality briquettes.

Similar studies are undertaken in other parts of the country to validate the findings of this study since it was limited to Kampala district.

Further research on financial feasibility and value addition of briquettes should be carried out.

\section{ACKNOWLEDGEMENTS}

We are grateful to Mr.Ziwa Hillington from Green Bio Energy limited, Mr. Essien Joel at Energy for Impact, Ms. Catherine Nakitende from King Fire limited and Ms. Akumu Justine from Ministry of Energy and Mineral Development for the technical support and assistance in respondent identification. 


\section{REFERENCES}

Akowuah, J.O.; Kemausuor, F.; Mitchual, S.J. 2012. Physico-Chemical Characteristics and Market Potential of Sawdust charcharcoal Briquette. In Proceedings of the 55th International Convention of Society of Wood Science and Technology. Beijing, China. pp.1-11

Bagabo, S.; Kaluya, G.; Balitta, P.; Mukose, M. 2014. Assessing the feasibility of commercial charcharcoal production systems in Uganda. Report Produced for FAO and Sawlog Production Grant Scheme by Integrated Rural Development Initiatives 1(1): 12-15.

Dasappa, S. 2011. Potential of biomass energy for electricity generation in Sub-Saharan Africa. Energy Sustain Dev 15(1): 203-233.

Ferguson, H. 2012. Briquette Businesses in Uganda. The potential for briquette enterprises to address the sustainability of the Ugandan biomass fuel market. GVEP International: London, UK. pp.7-9. http://wastetowealth.livingearth.org.uk/wpcontent/uploads/2013/10/briquette_businesses_in_uganda.pdf

Fund, C. 2003. Feasibility and impact assessment report for project to briquette municipal solid waste for use as a cooking fuel in Rwanda. pp.5-12. https://www.cleancookingalliance.org/binary-data/RESOURCE/ file/000/000/57-1.pdf

Karunanithy, C.; Wang, Y.; Muthukumarappan, K.; Pugalendhi, S. 2012. Physiochemical characterization of briquettes made from different feedstocks. Biotechnology Research International 8(2):1-2.

Mahoro, B.G.; Eniru, E.I.; Omuna, D.; Yusuf, A.A. 2017. Performance of Biomass Briquettes as an Alternative Energy Source Compared to Wood charcharcoal in Uganda. International Journal of Scientific Engineering and Science 1(6): 55-60. http://hdl.handle.net/20.500.12306/1584

Ministry of Energy and Mineral Development. MEMD. 2016. National charcoal Survey for Uganda 2015. Final Report. pp 1-134. https://unreeea.org/wpcontent/uploads/2018/10/National-Charcoal-Survey_ uganda.pdf

Mutea, E. 2015. Socio-economic factors influencing adoption of improved biomass energy technologies in rural and urban households in Kitui, Kenya. Masters of Arts in Environmental Planning and Management. University of Nairobi. http://hdl.handle.net/11295/94631

Mwampamba, T.H.; Owen, M.; Pigaht, M. 2013. Opportunities, challenges and way forward for the charcharcoal briquette industry in Sub-Saharan Africa. Energy for Sustainable Development 17(2): 158-170. https://doi.org/10.1016/j.esd.2012.10.006

Namaalwa, J.; Hofstad, O.; Sankhayan, P. L. 2009. Achieving sustainable charcharcoal supply from woodlands to urban consumers in Kampala, Uganda. International Forestry Review 11(1): 64-78.

Njenga, M.; Karanja, N.; Prain, G.; Malii, J.; Munyao, P.; Gathuru, K. 2009. Community-based energy briquette production from urban organic waste at Kahawa Soweto informal settlement, Nairobi. Urban Harvest Working Paper Series 5. International Potato Center: Lima, Peru.

Oladeji, J.T. 2015. Theoretical aspects of biomass briquetting: a review study. Journal of Energy Technologies and Policy 5(3): 72-81. http://citeseerx.ist.psu.edu/viewdoc/download?doi=10.1.1.948.9349\&rep=rep1\&type $=$ pdf

Spirchez, C.; Lunguleasa, A.; Matei, M. 2018. Particularities of hollow-core briquettes obtained out of spruce and oak wooden waste. Maderas. Cienc-Tecnol 20(1): 139-152. http://dx.doi.org/10.4067/S0718$221 \mathrm{X} 2018005001201$

Sseruwagi, R.; Bukenya, H. 2016. Effectiveness of briquettes as an alternative cooking fuel for households in Uganda. https://www.academia.edu/download/43254174/Academic_paper.pdf.

UBOS. 2014. Census Population. Uganda National Population and Housing Census Resulte. pp. 8-15. https://www.ubos.org/wpcontent/uploads/publications/03_20182014_National_Census_Main_Report.pdf 